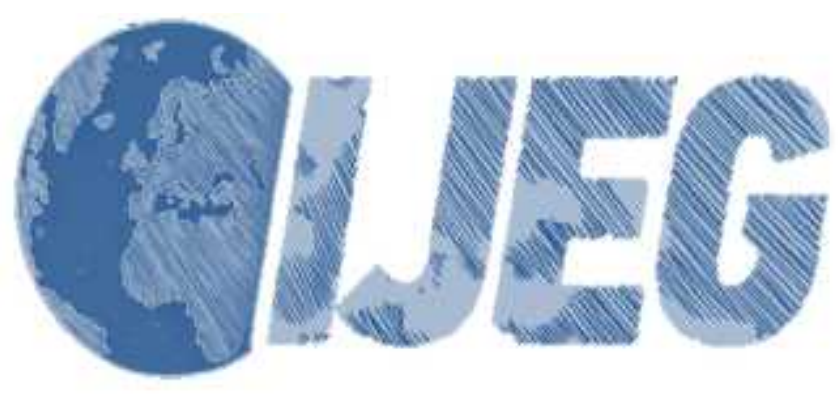

International Journal of Engineering and Geosciences (IJEG), Vol; 2; , Issue; 02, pp. 52-60, June, 2017, ISSN 2548-0960, Turkey, DOI: 10.26833/ijeg.298951

\title{
A COMPARISON OF THE CLASSIFICATION ACCURACIES IN DETERMINING THE LAND COVER OF KAD RL REGION OF TURKEY BY USING THE PIXEL BASED AND OBJECT BASED CLASSIFICATION ALGORITHMS
}

\author{
Karakus, P., ${ }^{1 *}$ Karabork, H., ${ }^{1}$ Kaya, S., ${ }^{2}$ \\ ${ }^{1}$ Selcuk University, Engineering Faculty, Department of Geomatic Engineering, Konya, Turkey \\ (pukarakus@gmail.com);(karabork@selcuk.edu.tr); \\ ${ }^{2}$ Istanbul Technical University, Civil Engineering Faculty, Department of Geomatic Engineering, Istanbul, Turkey \\ (kayasina@itü.edu.tr)
}

*Corresponding Author, Received: 20/03/2017, Accepted: 03/06/2017

\begin{abstract}
Pixel and object-based classification methods have been used for the determination of land cover. Pixel based classification methods suffer from salt and pepper effect. So pixel based classification methods cannot reach the accuracy of the object based classification. In order to eliminate the salt and pepper effect on the remote sensing classification accuracy and improve the result maps created as a result of the classification and further improve the classification accuracy in pixel based classification, it is recommended that the sieve class, clump class and majority analyses - which are ordinarily applied to high resolution images in this study by using the pixel based classification method. So the effect of these analyzes on low and medium resolution satellite images are unknown. With the SPOT 5 satellite image, this study will investigate how much this analysis affects the accuracy of classification. The classification includes the following categories: sun flowers, corns, peanuts, trees, roads, residential areas and water resources. In this study, the object based classification method was compared with three pixel based classification methods, namely the support vector machines, maximum likelihood method and spectral angle mapper method. The following general accuracy and kappa values were obtained from the methods in question: Object based classification method (96\% accuracy, kappa value of 0,949), maximum likelihood method (90.99\% accuracy, kappa value of 0,67), support vector machines (92.06 accuracy, kappa value of 0.70 ), spectral angle mapper method ( $93.88 \%$ accuracy, kappa value of 0,78 ). Following the pixel based classification process, the total accuracy and kappa values of the classified image was improved through the application of sieve class, clump class and majority analyses. As a result of the analyses conducted on the pixel based classification methods, the following general accuracy and kappa values were obtained for the following pixel based classification methods: maximum likelihood method (92.91\% accuracy, kappa value of 0,73), support vector machines (93.13\% accuracy, kappa value of 0.74 ) and spectral angle mapper method (95.62\% accuracy, kappa value of 0,88 ). As a result of the analyses applied to the pixel based classification method, the classification accuracy produced similar results to that of the object based classification accuracy. To the best knowledge our author this is the first study dealing with this study area. So the authors think that this paper present a different point of view for interested researchers in this study area.
\end{abstract}

Keywords: Object based classification, maximum likelihood method, support vector machine, spectral angle mapper, post classification. 


\section{INTRODUCTION}

Image classification methods are commonly used in determining the land cover due to their synoptic point of view and ability to operate in larger areas. Image classification involves the categorization of each pixel in an image. General image classification is done in two general approaches, namely the pixel based classification method and object based classification method. Despite the general view that the object based classification produces better results (Willhauck et al.,2000; Jensen et al., 2006; Yan et al., 2006; Hong et al., 2007; Platt and Rapoza, 2008; Weih and Riggan 2010; Whiteside et al., 2011; Myint et al., 2011; Meneguzzo et al.,2013; Varela et al.,2008; Michez,2016), there have nevertheless been studies conducted with a view to achieving high accuracy out of the pixel based methods in a classification. Support vector machines and the artificial neural networks method were found to have produced more accurate results compared to the maximum likelihood method (Foody and Mathur, 2004; Pal and Mather, 2005; Oommen et al., 2008; Naguib et al., 2009; Sakieh et al. 2016). When the pixel based and supervised classification algorithms -namely the maximum likelihood method, neural networks method and decision tree methods were compared, it was established that the support vector machines produced the highest accuracies (Huang et al., 2002). When the support vector machine was compared to the Conditional Random Fields (CRF) method, the conditional random fields method was found to have produced more accurate results (Hoberg and Müller, 2011). When the support vector machines were compared with the supervised pixel based classification methods -including minimum distance, Mahalanobis distance, maximum likelihood and spectral angle mapper (SAM) methods, it was found that the maximum likelihood method and support vector machines delivered a better performance (Yang et al., 2011). The crop index, maximum likelihood and Spectral Angle Mapper (SAM) supervised classification methods have been compared in terms of determining the weeds in legumes and grains, as a result of which the spectral angle mapper (SAM) method was found to be less accurate (Castro et al., 2012). By employing the LISS IV data, the support vector machines, spectral angle mapper and artificial neural networks methods have been used in the crop classification. The support vector machines and artificial neural networks have provided more accurate results (Kumar et al., 2015).

In remote sensing studies, the concept of accuracy which is known as the consistency between the real class and the class label assigned to a pixel- and real class can be identified by actually going out on the field or by viewing an aerial photograph, satellite image. The classification accuracy can be improved for single images or time sequenced images by combining the multi-sourced data (Lunetta and Balogh,1999) and by establishing different spectral features (Wilson and Sader, 2002) and by developing new methods (Murai and Omatu,1997; Maxwell et al.,2004; Sun and Schulz, 2015). In remote sensing, assigning pixels to a class other than their designated class is called the salt and pepper effect. Despite the fact that Castillejo-Gonzalez et al. (2009) has talked about the significance of the salt and pepper effect on the high resolution satellite images and suggested that the classified maps should be improved to mitigate such errors and that a $5 * 5$ majority filter be applied to be able to achieve higher accuracies, it is not known to what extent the analyses conducted following the low and mid resolution classifications actually influence the classification results. Considering the costs in agricultural studies, it is observed that the studies are mostly conducted with mid and low resolution satellite images (Yang et al.,2011;Hoberg and Müller, 2011; Huang et al.,2002; Faria et al.,2012).

In this study, the mid resolution SPOT 5 satellite image has been subjected to sieve, clump and majority analyses -after having been initially classified through maximum likelihood, support vector machines, spectral angle mapper methods-, the effects of the classification results discussed and their accuracies have been compared with the object based classification methods. To the best knowledge author this is the first study dealing with this study area. So the authors think that this paper provide a different point of view for interested researchers in this area. Because of this area has previously unstudied very fertile farm lands.

\section{METHODS}

\subsection{Study Area}

The study area is located in the fertile lands of the Eastern Mediterranean Region of Turkey, covering the areas of Ceyhan, Osmaniye, Kadirli and Kozan, on the east bank of the Ceyhan River, east of Çukurova. Osmaniye is located between 35 52' - 36 42' East Longitude and between 36 57' - 37 45' North Latitude. Osmaniye is surrounded by Gaziantep in the east, Hatay in the south, Adana in the west and Kahramanmaras in the north. The province is approximately $7-8 \mathrm{~km}$. away from the Gulf of skenderun in the southwest.

Osmaniye is a province that agriculture has dominant structure. City of the total land area (376.70 ha), 97.419 hectares of farm land, 130 hectares of fallow land, 4.535 hectares of vegetable gardens, 13.284 ha of fruit-bond, are the sum of 115.368 agricultural land. When epiphora situation analysis of agricultural land examined, total agricultural land (124.800) of \%69.3 (86.523) irrigated. \% 72.4 of these irrigated land irrigate.

The area is a complex mosaic of several land cover types including corn, sunflower, peanut, trees, road, residential and water resource. This spatially complex area was chosen to highlight the differences between the image classification approaches. This area has very fertile soil. It is an area untouched in terms of remote sensing studies.

\subsection{Material}

SPOT 5 satellite image has $10 \mathrm{~m}$. spatial resolution with 4 spectral band (Red, Green, Blue, NIR). The satellite has two HRG sensors that are capable of capturing high resolution data. Through those sensors, it is possible to obtain 2.5 to 5 meter resolution data in panchromatic detection mode, and 10 meter resolution or better data in multi-spectral detection mode. Moreover, the satellite also has a HRS sensor that can detect data in panchromatic mode. The HRS is capable of obtaining stereo image pairs that can identify the surface printing through forward and backward sights. 
Stereo image pairs are used to establish Numerical Elevation Models that provide data regarding the elevation from the earth surface (TU-UHUZAM). It has a synchronous near polar orbit. Its orbital altitude is around $822 \mathrm{~km}$ (in Ecuador). Its orbital period is 26 days. Its scan area is $60 \mathrm{~km} * 60 \mathrm{~km}$. Its radiometric resolution is 8 bits and spatial resolution Pan: $2.5 \mathrm{~m}$ (production from a $2 * 5 \mathrm{~m}$ resolution framework) Pan: 5m (rare) MS: $10 \mathrm{~m}$ (rare) SWI: 20m (rare).

The SPOT 5 satellite image was taken on May 5, 2013, at 08:13:12 am. Multispectral image was used in study. Image was taken with ortho geometric processing level. Image incidence angle was 5.465347, sun azimuth was 135.108586 and sun elevation was 62.354325 .

Sun flower and corn are planted in early March in our study area. Corn and sun flower are very green in May. So date of acquisition is convenient for our study. Comprehensive field survey data were obtained directly from farmers and village headman by interviews. 50 training data (number of fields) selected for classifier training. Another 50 field data set used for validation. Test and verification data were randomly selected.

The reference spectra can either be taken from laboratory measurement or field measurements or extracted directly from the image. We are taken spectra values field measurement on July 1, 2013 for spectral angle mapper classification method.

\subsection{Image Preprocessing}

Because study area became range of two middle slices, coordinates transformed geographic coordinates with geometric correction. Geometric correction of the satellite image has been done using the ENVI software. Geometric transformation of the image was obtained with 0.32 pixels RMSE (Root Mean Square Estimation) by means of second degree polynomial transformation by the help of 16 land control points acquired by RTKGPS and the nearest neighbor resampling method (Orhan et al. 2014; Dymond and Shepherd 2004).

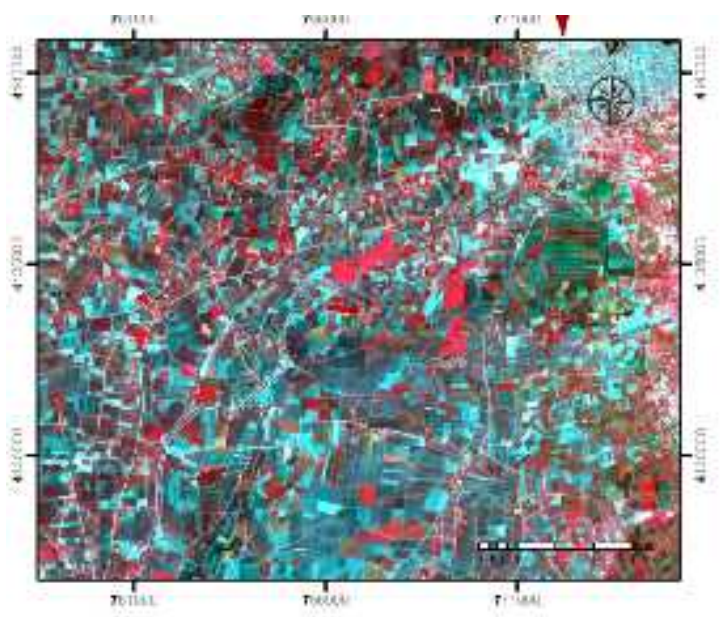

Figure 1. The study area that covers the provinces of Kadirli, Ceyhan and Osmaniye, Turkey.

\subsection{Pixel-Based Classification}

Being a traditional classification method, the pixel based classification takes pixel as its primary unit. In the pixel based method, where each pixel is compared in terms of its spectral proximity to the class to which it will be assigned (Casals-Carrasco et al., 2000). The pixel based classification method is divided into two categories, namely supervised classification and unsupervised classification methods.

The unsupervised classification does not contain any data with respect to the area to be classified. It uses the algorithms that classify such elements based on natural groupings or aggregation that are presently available in the digital values of the image. Since it uses the classification of natural groupings, the classes created as a result of the classification are those of the spectral classes that have been identified prior to the process (Ekercin, 2007). The most commonly used unsupervised classification methods include the k-means clustering, Euclidean distance, mahalanobis distance, sequential clustering, statistical clustering, repeated successive clustering (ISODATA) and RGB clustering.

In the supervised classification method, however, the spectral features of each object to be classified are defined based on the sample areas representing the earth, and thus the feature files are created. The feature file sampling the test area is then applied to the image data, thereby including each image data into the class that it resembles the most (Ekercin, 2007). The most commonly used supervised classification methods include the Maximum Likelihood Classification, the minimum Distance classification and the Parallelpiped Classification methods.

\subsubsection{Maximum Likelihood Classification}

A pixel has the highest probability value assigned to the class in the maximum likelihood method. A probability distribution model is needed to calculate these probabilities. The normal distribution model is usually used in practice. Accordingly, each class is considered to have a normal distribution of training data. In reality, this acceptance is not very correct. But the normal distribution in the modeling of optical remote sensing data is found to be appropriate. Normal distribution is determined by mean and variance parameters for single variable, mean vector and covariance vector for multivariate data (Sunar et al.,2016). The multidimensional normal distribution probability density function is as follows (Eq.1).

$f(x)=\frac{1}{(2 \pi)^{\frac{x}{2}} \sqrt{\mid \Sigma}} e^{\frac{-1}{2}(x-\mu)^{t} \sum /(x-\mu)}$

$\boldsymbol{\mu}$ mean vector,

$\sum$ covariance matrix,

I $\mid$ Determinism of the covariance matrix

The distribution of each class is determined by the mean vector and the covariance matrix calculated from the training patterns. The probabilities of unknown pixels belonging to the categories can be calculated based on the distribution models calculated from the training data for all classes. As a result, the pixels are most likely assigned to the classes to which they belong (Sunar et al.,2016). 


\subsubsection{Support Vector Machines}

The use of support vector machines (SVM) as image classification in remote sensing has first been suggested by Gualtieri and Cromp (1998). The idea has been put forward in more detail by Burges,(1998); Huang et al.,(2002); Richards and Jia, (2006). SVM classification is a controlled classification algorithm that is based on statistical learning theory. At first, the mathematical algorithms of the SVM were designed for the classification of the two class linear data, but they were later generalized for the classification of the multi class and non linear data. The working principle of the SVM is based on estimating the most suitable decision function that is capable of separating the two classes from each other, in other words identifying the subplatform that can separate the two classes in the most appropriate way (Vapnik, 1995; Vapnik, 2000). Being successfully used in a number of fields, the recent years have seen many studies conducted for the use of SVMs in the field of remote sensing (Foody et al., 2004, Melgani et al., 2004, Pal et al., 2005).

\subsubsection{Spectral Angle Mapping (SAM)}

In the Spectral Angle Mapper (SAM) method that allows the performance of Object Based Reference Spectra summation (endmember) analysis, the angle between the reference vector created based on the spectral reflectance data that is used as reference- and the vector which has been created out of the satellite image pixel values whose class has not yet been assigned is calculated. If the calculated angle is less than or equal to the likelihood value that has been previously designated for the reference spectra class, the pixel with unknown class is assigned to the relevant reference spectra class (Gürsoy et al., 2013).

By using the SAM algorithm, the spectral angle between the unknown spectrum $(\mathrm{t})$ and the reference spectrum (r) is calculated for each pixel in radians (Kruse et al., 2003). The spectral angle is calculated by using the following equation. The unknown pixel is assigned to the reference spectrum (class) that has the least spectral angle value with itself (Eq. 2) .

$\alpha=\cos ^{-1}\left[\frac{\sum_{i=1}^{n} t_{l} r_{i}}{\sqrt{\sum_{i=1}^{n} t_{l}^{2}} \cdot \sqrt{\sum_{i=1}^{n} r_{\zeta}^{2}}}\right]$

$\mathrm{n}=$ Number of bands

$\boldsymbol{t},=$ Test spectrum

$r_{,}=$Reference spectrum

$\alpha=$ Spectral angle

\subsection{Post Classification (Sieve-Clump- Majority/Minortiy Analysis)}

Classified images often have a salt and pepper effect. Post classification processes were applied over a classified image to eliminate salt and pepper effect, and to generate an apparently less noisy image (Al-Ahmadi and Hames, 2009). Sieve, clump and majority/minority analysis have been usually applied to classified images. Sieve analyses are applied first to remove isolated classified pixel. For this, if a pixel is included with pixels of the same class, the method search the neighboring 4 or 8 pixels. If the number of pixels in a class is less than a specified threshold value, those pixels are removed from the class. (Buddenbaum et al.,2005; Al-Ahmadi and Hames, 2009). Clump analysis is used to clump adjacent similarly classified areas with morphological operators. Low pass filtering could be used to smooth images that have speckle or holes in classified areas. Clumping classes solves a problem that the class information would be contaminated by adjacent class codes (Al-Ahmadi and Hames, 2009). Determining classes are clumped together. It called dilate operation. Another operation is erode operation. A kernel of size determines in this operation. The clump algorithm fills holes smaller than a given kernel. Then 'islands' of pixels smaller than the kernel removes (Buddenbaum et al.,2005; Al-Ahmadi and Hames, 2009). Majority/Minority analysis is applied after sieve and clump analysis to classified images. Majority analyses are used to change false pixels in a large single class. Minority analysis is used to replace center pixel in the kernel with the class value that the minority of the pixels in the kernel (URL-1).

Above mentioned these three post classification processes were applied on the images that are classified by maximum likelihood, support vector machine, spectral angle mapper and object based classification methods.

\subsection{Object-Based Classification}

Being a traditional classification method, pixel based classification takes pixel as its primary unit. However, the heterogeneity of pixels and the variability of crops in the study area has led to an increase in the use of object based methods in the remote sensing studies (Blaschke, 2010).

Analyzing the remote sensing data with the traditional pixel based method has presented a problem in identifying some of the crops due to the variability of the crop patterns, spectral similarity, mixed up pixels and pixel heterogeneity. In order to overcome this problem, spectral, textural and hierarchical features are added to the object based image analysis following the segmentation of the image (Pena-Barragan et al., 2011).

The object based classification involves segmentation and classification stages. The segmentation stage is the most important stage that directly determines the classification accuracy. The image segmentation algorithms are aggregated in two categories, namely the area based and boundary based categories. In the boundary based segmentation algorithms, boundaries are determined by checking whether the objects are continuous. In area based methods, however, the areas are determined based on their similarity (Zhang, 1997). 
The homogeneous objects obtained as a result of the segmentation process are used as classification units.

The objects representing the spectrally varying land cover type at pixel level are formed through segmentation. This way, the 'salt and pepper' effect, resulting from the pixel based classification, is eliminated. Another advantage of this unit is that, instead of using random units such as pixels, it uses the objects that represent the real world features better than pixels. Moreover, it has the extra advantages that include the shape features, the hierarchical structures of classes and objects and the topological structures of objects. The object based analyses allow the creation of a set of rules that can utilize the scenes that are capable of producing a repetitive method. One of the disadvantages of this method is that it requires the preliminary data of the land cover type that cannot be found at all times. Another disadvantage associated with this method is the segmentation between the objects that can utilize mainframe computer memory and the resulting topological relationships. The lack of definite algorithms and parameters in creating image objects is yet another disadvantage of this method. Despite the fact that the local variances are used in recent years to determine the appropriate segmentation scales, the appropriateness of the segmentation is mostly evaluated through visual inspections (Whiteside et al., 2011; Dragu et al., 2010).

Image segmentation as the initial stage of object based classification has an important role in the performance of object based classification. The more accurate segmentation increases the results of classification. There are a lot of techniques for image segmentation (Dey, 2011). Multi-resolution segmentation, which was proposed by Baatz and Schape (2000), is one of the most powerful region based segmentation algorithms that have been implemented in commercial software, eCognition (Definiens Imaging, 2009). However, this algorithm needs a set of optimum parameters which usually obtained by trial and error method. This technique relies on the user's experience. The multi resolution segmentation is a bottom-up region merging step starting with one pixel. The method performs based on two heterogeneity criteria, geometrical and spectral. Smaller image objects are merged into bigger ones. The bigger image objects form segmentation with object on different scales. The created objects undergo an optimization process. The optimization process tries to minimize the internal weighted heterogeneity of each object. The smallest possible growth is calculated for each object. If the object properties exceed the heterogeneity threshold, the growth of this object stops. Heterogeneity is defined as the color and shape of the object. Shape, compactness/smoothness and scale parameters are userdefined parameters. Scale parameter determines the average image object size. An appropriate value of scale parameter determine with trial and error method (Dragut et al.,2010). Compactness criterion minimizes the deviation from the ideal compact form. If the shape factor is weighted with high values, the influence of color values is lower. Shape factor is also necessary to calibrate a compactness and smoothness value influencing the object generation. If the compactness is weighted low values, the smoothness factor is increased. An object with a more linear shape is obtained (Dragut et al., 2010; Definiens, Developer 7 User Guide).

\section{RESULTS}

The pixel based classification processes have been realized by using the ENVI software, and the object based classification processes by using the Definiens eCognition Developer.

The first stage of the object based classification process involves segmentation (Figure 2). Here, a multi resolution segmentation process was implemented in the eCognition software. In this particular segmentation algorithm, the parameters that determine the classification accuracy are that of the scale, shape and integrity parameters. For this study, scale has been chosen as 70, shape as 0,2 and the compactness as 0,6 . Such parameters are the ones that most realistically represent the test farms.

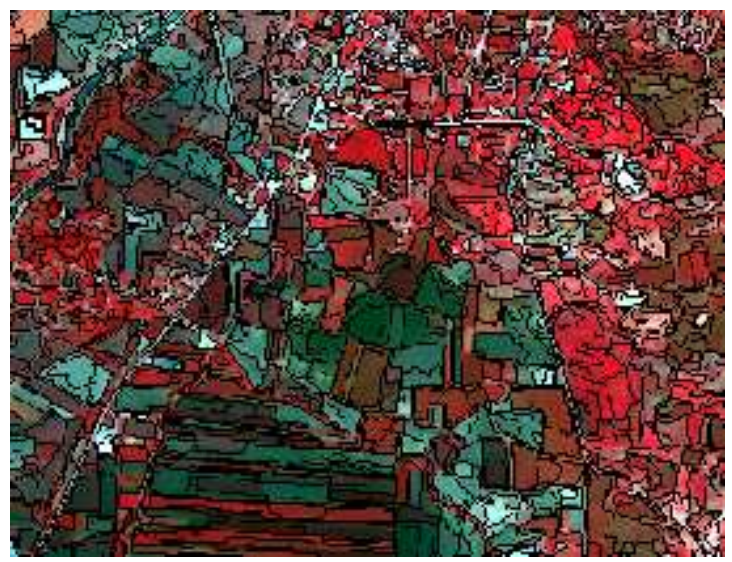

Figure 2. Segments in the segmentation stage of the object based classification

7 classes have been identified in the classification stage, representing water resources, sun flowers, corns, peanuts, residential areas, roads and trees. In the classification stage, classification was performed based on the nearest neighbor method (Figure 3).

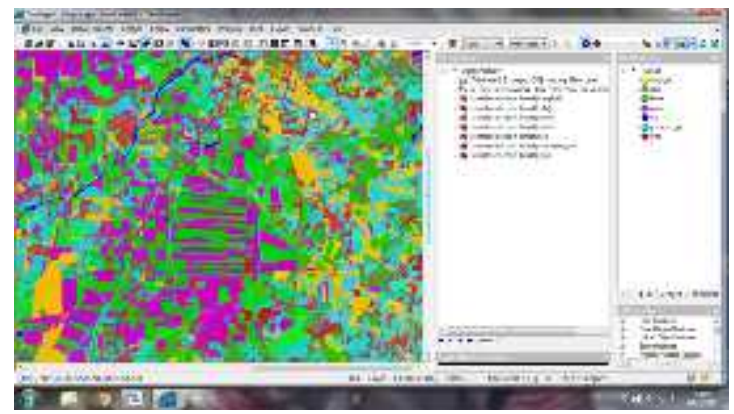

Figure 3. Results of the object based classification

In order to avoid a subjective estimation in remote sensing, a confusion matrix, which determines the accuracy of the method by comparing the confirmed land data with the classified pixel percentage, is used (Congalton, 1991). General accuracy in the confusion matrix reveals the percentage of the classified pixels in 
an accurate manner. Producer accuracy and omission error presents the likelihood of the classified pixel being actually represented in that class. The acceptable general accuracy is $85 \%$ (Foody, 2002). User accuracy and omission error shows how well the pixels in training set have been classified (Rogan et al., 2002). It is reported that a classification is strong when the Kappa coefficient is over 0.8 (Landis and Kock 1977). In their study, Montserud and Leamans (1992) have suggested that the kappa value cannot be over 0.75 by chance.

The accuracy analysis of the classification results have been performed based on the 'Error Matrix based TTA Mask'. The classified image has been compared with the sample areas -chosen as test data through the segmented image- and the error matrices have been obtained. The error matrix achieved from the satellite image is presented in the Table 1. It has been observed that the classification method between the classes of roads and residential areas has been somewhat problematic (Table 1).

Table 1. Error matrix for the object based classification

\begin{tabular}{|c|c|c|c|c|}
\hline $\begin{array}{l}\text { User/ } \\
\text { Reference }\end{array}$ & Sun flower & Peanut & Corn & Road \\
\hline \multicolumn{5}{|l|}{$\begin{array}{l}\text { Confusion } \\
\text { matrix }\end{array}$} \\
\hline Sunflowers & 13605 & & & \\
\hline Peanuts & & 11595 & 226 & \\
\hline Corns & & & 12853 & \\
\hline Roads & & & & 1465 \\
\hline \multicolumn{5}{|l|}{$\begin{array}{l}\text { Water } \\
\text { resources }\end{array}$} \\
\hline $\begin{array}{l}\text { Residential } \\
\text { areas }\end{array}$ & & & & 236 \\
\hline \multicolumn{5}{|l|}{ Trees } \\
\hline Total & 13605 & 11595 & 13079 & 1701 \\
\hline $\begin{array}{l}\text { Producer } \\
\text { accuracy }(\%)\end{array}$ & 100 & 100 & 98.27 & 86.12 \\
\hline $\begin{array}{l}\text { User } \\
\text { accuracy }(\%)\end{array}$ & 100 & 98.09 & 100 & 100 \\
\hline $\begin{array}{l}\text { General } \\
\text { accuracy }(\%)\end{array}$ & 96 & & & \\
\hline \multirow[t]{2}{*}{ Kappa (\%) } & 0.949 & & & \\
\hline & $\begin{array}{l}\text { Water } \\
\text { resource }\end{array}$ & $\begin{array}{l}\text { Residential } \\
\text { area }\end{array}$ & Tree & Total \\
\hline \multicolumn{5}{|l|}{$\begin{array}{l}\text { Confusion } \\
\text { matrix }\end{array}$} \\
\hline Sunflowers & & & & 1365 \\
\hline Peanuts & & & & 11821 \\
\hline Corns & & & & 12853 \\
\hline Roads & & & & 1465 \\
\hline $\begin{array}{l}\text { Water } \\
\text { resources }\end{array}$ & 5330 & 1556 & & 6886 \\
\hline $\begin{array}{l}\text { Residential } \\
\text { areas }\end{array}$ & & 2821 & & 3057 \\
\hline Trees & & & 672 & 672 \\
\hline Total & 5330 & 4377 & 672 & \\
\hline $\begin{array}{l}\text { Producer } \\
\text { accuracy }(\%)\end{array}$ & 100 & 64.45 & 100 & \\
\hline $\begin{array}{l}\text { User } \\
\text { accuracy }(\%)\end{array}$ & 77.4 & 92.28 & 100 & \\
\hline \multicolumn{5}{|l|}{$\begin{array}{l}\text { General } \\
\text { accuracy (\%) }\end{array}$} \\
\hline Kappa (\%) & & & & \\
\hline
\end{tabular}

The pixel-based classification employed the maximum likelihood, support vector machines, spectral angle mapping and spectral data difference methods. 7 classes have been identified in the classification stage, representing water resources, sun flowers, corns, peanuts, residential areas, roads and trees. ROIs have been identified for the classification and control, containing two different data sets. In order to improve the classification accuracy, the images obtained as a result of the classification have been subject to the sieve class, clump class and majority analyses.
Table 2. The classification accuracies obtained as a result of pixel based classification

\begin{tabular}{|l|l|l|}
\hline & General accuracy & Kappa \\
\hline Maximum likelihood (\%) & 90.99 & 0.67 \\
\hline Maximum likelihood & & \\
\hline sieve+clump+majority Analysis (\%) & 92.91 & 0.73 \\
\hline Support vector machines (\%) & & \\
\hline Support vector machines & 92.06 & 0.70 \\
\hline sieve+clump+majority Analysis (\%) & 93.13 & 0.74 \\
\hline Spectral angle mapping (\%) & & \\
\hline Spectral angle mapping & 93.88 & 0.78 \\
\hline sieve+clump+majority Analysis (\%) & 95.62 & \\
\hline
\end{tabular}

Since most of the roads in the area are unpaved roads, the classes of roads and unpaved roads have been combined into a single class under 'roads'. The fact that the pixels were mixed up in the predominantly urbanized areas has caused heterogeneity. For this reason, the classes of roads and residential areas could not be separated from each other in most cases. In general, however, the accuracy analyses of both classifications yielded fairly similar results.

\section{CONCLUSION and DISCUSSION}

In this study, the object based classification method has been compared with the pixel based classification methods and the effect of sieve, clump, majority analysis applied to the pixel based classifications (maximum likelihood classification, support vector machine and spectral angle mapper classification) on the medium resolution SPOT 5 satellite image was investigated. The SPOT 5 satellite image of Osmaniye region, taken in May 2013, has been used for making such comparison in this study. The maximum likelihood method $(90.99 \%$ accuracy, kappa value of 0,67 ), support vector machines method $(92,06 \%$ accuracy, kappa value of 0,70$)$ and the spectral angle mapping method $(93.88 \%$ accuracy, kappa value of 0,78 ) have been used as pixel based classification methods in this study area. In order to improve the classification accuracy, the images classified by pixel based methods have been subject to the sieve class, clump class and majority analyses. As a result of those analyses, the accuracy of the maximum likelihood method $(92,91 \%$ accuracy, kappa value of 0,73), support vector machines method $(93,13 \%$ accuracy, kappa value of 0,74$)$ and the spectral angle mapping method $(95,62 \%$ accuracy, kappa value of 0,88 ) have improved and the overall classification accuracy has come closer to the accuracy of the object based methods ( $96 \%$ accuracy, kappa value of 0,95)in this study area. The kappa values, in particular, considerably increased as a result of those analyses. It is 
believed that the reason for such an improvement in the pixel based classification accuracy is due to the selection of the test and control farms that best represent the land cover and having taken the satellite image when the selected crops had the best reflection values. This way, fairly accurate classification results have been obtained by using a specific-dated mid-resolution satellite image in this study area. It was observed that the satellite image in question was inadequate in terms of distinguishing the buildings therein. Due to the resolution of the satellite image, the classes of residential areas and roads could not be separated from each other by using the object based classification method. Despite the fact that the support vector machines method seems to produce more accurate results according to the literature, we have obtained more accurate results from the SAM method in the present study. It is believed that high accuracy obtained as a result of this study has been due to the selection of the projection values that best represent the crop types. Considering the cost and accessibility issues of the crop type determination studies in the literature, it is observed that such studies usually use low and mid resolution satellite images. It has been established that the application of sieve class, clump class and majority analyses to the pixel based classification results achieved through low and mid resolution satellite images- in the literature has produced classification results, and particularly the kappa values, that are considerably close to that of the object based classification results. Results show that object-based classification results is more accurate than the other methods. Object-based classification accuracy results have not been achieved even when the pixel-based classification accuracy results are increased with various analyses.

\section{REFERENCES}

Baatz, M., Schape, A., 2000. Multi resolution segmentation-an optimization approach for high quality multi scale image segmentation. Angewandte Geographische Informations verarbeitung XII. Karlsruhe, Germany, pp. 12-23.

Blaschke, T. 2010. Object Based Image Analysis for Remote Sensing. ISPRS Journal of Photogrammetry and Remote Sensing, 65, 2-16.

Buddenbaum, H., Schlerf M.,Hill J., 2005. Classification of coniferous tree species and age classes using hyperspectral data and geostatistical methods. International Journal of Remote Sensing, 26( 24),54535465.

Burges, C.,J,C., 1998. ATutorial on Support Vector Machines for Pattern Recognition. Data Mining and Knowledge Discovery, 2,121-167.

Casals-Carrasco, P., Kubo,S., Babu Madhavan, B., 2000. Application of Spektral Mixture Analysis For Terrain Evaluation Studies. International Journal Of Remote Sensing, 21, 3039-3055.

Castillejo-Gonzalez I.L., López-Granados F., GarciaFerrer A., Peña-Barragan J.M., Jurado-Expósito Sanchez-de la Orden M., Gonzalez-Audicana M., 2009.
Object- and pixel-based analysis for mapping crops and their agro-environmental associated measures using QuickBird imagery. Computers and Electronics in Agriculture, 68,207-215

Castro, A. I., Jurado-Expósito, M., Pena-Barragan, J. M., López-Granados F., 2012. Airborne multi-spectral imagery for mapping cruciferous weeds in cereal and legume crops. Precision Agriculture, 13 (3), 302-321.

Congalton, R.G., 1991. A review of assessing the accuracy of classification of remotely sensed data.Remote Sens. Environ., 37 ,35-46.

Definiens, Developer 7, User Guide

Dey, V., 2011. A Supervised Approach for the Estimation of Parameters of Multiresolution Segmentation and its Application in Building Feature Extraction from VHR Imagery. M.Sc.E Thesis, Department of Geodesy and Geomatics Engineering Technical Report No. 278, University of New Brunswick, Fredericton, New Brunswick, Canada, 162.

Dragut, L., Tiede, D., Levick, S.R., 2010. ESP: a tool to estimate scale parameter for multiresolution image segmentation of remotely sensed data, International Journal of Geographical Information Science, 24, 859871

Dymond, J. R., Shepherd, J. D. 2004. The spatial distribution of indigenous forest and its composition in the Wellington region, New Zealand, from ETM+ satellite imagery. Remote Sensing of Environment, 90(1),116-125.

Ekercin, S., 2007. Uzaktan Algılama Ve Coğrafi Bilgi Sistemleri Entegrasyonu le Tuz Gölü Ve Yakın Çevresinin Zamana Bağlı Değişim Analizi. Doktora Tezi, TÜ.

Faria, F.,A.,Dos Santos, J.,A.,Torres, R. Da S., Rocha, A., Falcao, A., 2012. Automatic Fusion Of RegionBased Classifiers For Coffee Crop Recognition. IEEE, 978-1-4673-1159-5/12.

Foody, G.M., 2002. Status of land cover classification accuracy assessment,Remote Sens. Environ., 80 , 185201

Foody, G.M., Mathur, A., 2004. A Relative Evaluation Of Multiclass Image Classification By Support Vector Machines. IEEE Transactions On Geoscience And Remote Sensing, 42, 1335-1343.

Gualtieri, J.A., Cromp, R.F, 1998. Support Vector Machines For Hyperspectral Remote Sensing Classification. Proc. SPIE, 3584, 221-232.

Gürsoy, Ö., Kaya, Ş., Çakır, Z., 2013. Uydu görüntüleri ile yersel spektral ölçme verilerinin entegrasyonu. Havacılık ve Uzay Teknolojileri Dergisi,6(1),45-51. 
Hoberg, T., Müller, S., 2011. Multitemporal Crop Type Classification Using Conditional Random Fields and RapidEye Data. ISPRS, XXXVIII-4/W19, 115-121.

Hong, G., Zhang,Y, Zhang, A.,Zhou, F, Li, J., 2007. Fusion of Modis And Radarsat Data For Crop Type Classification- An Initial Study. ISPRS Workshop On Updating Geo-Spatial Databases With Imagery \& The 5th ISPRS Workshop On Dmgiss,Urumqin Xinjiang, Uygur,China.

Huang, C., Davis, L.S., Townshend, J.R.G., 2002. An Assesment of support vector Machines for Land Cover Classification. Int. J. Remote Sensing, 23,725-749.

\section{TÜ-UHUZAM Remote Sensing Laboratory www.cscrs.itu.edu.tr Accessed 19.10.2016}

Jensen, J. R., Garcia-Quijano, M., Hadley, B., Im, J., Wang, Z., Nel, A. L.,Teixeira, E., Davis, B. A., 2006. Remote Sensing Agricultural Crop Type For Sustainable Development In South Africa. Geocarto International, 21( 2), 5-18.

Kruse,F.A.,Boardman, J.W., and Huntington, J.F., 2003. Comparison of airborne hyperspectral data and EO-1 Hyperion for mineral mapping.IEEE Transactionson Geoscience and Remote Sensing, 41,1388-1400.

Kumar, P.,Dileep Gupt,a K., Mishra, V. N.,Prasad R., 2015. Comparison of support vector machine, artificial neural network, and spectral angle mapper algorithms for crop classification using LISS IV Data. International Journal of Remote Sensing, 36( 6), 1604-1617.

Landis, J.R., Kock, G.G., 1977. The measurement of observer agreement for categorical data Biometrics, 33 ,159-174

Lunetta, R.S.; Balogh, M.E., 1999. Application of multitemporal Landsat $5 \mathrm{TM}$ imagery for wetland Identification. Photogramm. Eng. Remote Sens. 65, 1303-1310.

Maxwell, S.K.; Nuckols, J.R.; Ward, M.H.; Hoffer, R.M., 2004. An automated approach to mapping corn from Landsat imagery. Comput. Electron. Agric., 43, $43-54$.

Melgani, F., Bruzzone, L., 2004. Classification of Hyperspectral Remote Sensing Images With Support Vector Machines, IEEE Transactions On Geoscience And Remote Sensing, 42(8), 1778-1790.

Meneguzzo, D.M. , Liknes, G. C. , Nelson, M. D., 2013. Mapping trees outside forests using high-resolution aerial imagery: a comparison of pixel- and object-based classification approaches. Environmental Monitoring and Assessment. 185(8), 6261-6275.

Michez, A., Piégay, H., Lisein, J., Claessens, H., Lejeune, P., 2016. Classification of riparian forest species and health condition using multi-temporal and hyperspatial imagery from unmanned aerial system. Environmental Monitoring and Assessment.188:146.
Montserud R.A., Leamans R., 1992. Comparing global vegetation maps with the kappa statistic Ecol. Model., $62,275-293$.

Murai, H.; Omatu, S., 1997. Remote sensing image analysis using a neural network and knowledge-based processing. Int. J. Remote Sens., 18, 811-828.

Myint,S.W., Gober, P.,Brazel, A., Grossman-Clarke,S., Weng,Q., 2011. Per-pixel vs. object-based classification of urban land cover extraction using high spatial resolution imagery. Remote sensing of environment, 115(5),1145-1161.

Naguib, A.M., Farag, M.A., Yahia, M.A., Ramadan H.H., Abd Elwahab M.S., 2009. Comparative study between support vector machines and neural networks for lithological discrimination using hyperspectral data. Egypt Journal of Remote Sensing and Space Science, $12,27-42$

Oommen, T., Misra, D., Twarakavi, N.K.C., Prakash A., Sahoo B., Bandopadhyay S., 2008. An objective analysis of support vector machine based classification for remote sensing. Mathematical Geosciences, 40, 409-422

Orhan, O., Ekercin, S., Dadaser-Celik, F., 2014.Use of Landsat Land Surface Temperature and Vegetation Indices for Monitoring Drought in the Salt Lake Basin Area, Turkey. The Scientific World Journal, doi:10.1155/2014/142939

Pal, M., Mather, P.M., 2005. Support Vector Machines For Classification in Remote Sensing. International Journal Of Remote Sensing, 26,1007-1011.

Pena-Barragan, J.,M., Ngugi, M.,K.,Plant, R.,E., Six, J., 2011. Object-Based Crop Identification using Multiple Vegetation Indices, Textural Features and Crop Phenology. Remote Sensing Of Environment, 115,13011306.

Platt, R.V, Rapoza, L., 2008. An evaluation of an objectoriented paradigm for land use/land cover classification. the Professional geographer, 60(1),87

Richards, J.A., Jia, X., 2006. Remote Sensing Digital Image Analysis(4. Edition), Germany:Springer.

Rogan, J., Franklin, J., Roberts, D.A., 2002. A comparison of methods for monitoring multitemporal vegetation change using Thematic Mapper imagery. Remote Sens. Environ., 80 ,143-156.

Sakieh, Y., Gholipour, M., Salmanmahiny, A., 2016. An integrated spectral-textural approach for environmental change monitoring and assessment: analyzing the dynamics of green covers in a highly developing region. Environmental Monitoring and Assessment.188:205.

Sun, L., and Schulz, K., 2015. The Improvement of Land Cover Classification by Thermal Remote Sensing. remote sensing, 7, 8369-8391. 
Sunar, F.,Özkan, Ç., Osmanoğlu, B., 2016. Uzaktan algılama, T.C. Anadolu Üniversitesi Yayını, No:2320, 4. Edition.

Vapnik, V.N., 1995. The Nature Of Statistical Learning Theory (1. Edition),New York: Springer-Verlag.

Vapnik, V.N., 2000. The Nature Of Statistical Learning Theory ( 2. Edition) New York: Springer-Verlag.

Varela, R. A. D., Ramil, Rego P., Calvo, Iglesias S., Muñoz Sobrino, C., 2008. Automatic Habitat Classification Methods Based On Satellite Images: A Practical Assessment In The $\mathrm{Nw}$ Iberia Coastal Mountains. Environmental Monitoring And Assessment.144(1),229-250.

Weih, R. C., Jr. and Riggan, N. D., Jr., 2010. ObjectBased Classification Vs. Pixel-Based Classification: Comparitive Importance Of Mult1-Resolution Imagery. The International Archives Of The Photogrammetry, Remote Sensing And Spatial Information Sciences, XXXVIII-4/C7.

Whiteside, T. G., Boggs, G. S., Maier, S. W, 2011. Comparing object-based and pixel-based classifications for mapping savannas. International Journal of Applied Earth Observation and Geoinformation, 13, 884-893.

Willhauck, G., Schneider, T., De Kok, R., Ammer U., 2000. Comparison of object-oriented classification techniques and standard image analysis for the use of change detection between SPOT multispectral satellite images and aerial photos.Proceedings of XIX ISPRS Congress, Amsterdam, July 16-22.

Yan,G.,Mas,J.F.,Maathuis, B.H.P.,Xiangmin, Z., Van Dijk, P.M, 2006. Comparison of pixel based and object oriented iamge classification approaches-A case study in a coal fire area, Wuda, nner Mongolia, China, International Journal of Remote Sensing, 27,4039-4055.

Yang, C., Everitt, J. H., Murden, D., 2011. Evaluating high resolution SPOT 5 satellite imagery for crop identification .Computers and Electronics in Agriculture 75( 2), 347-354.

Yonezawa, C., 2007. Maximum likelihood classification combined with spectral angle mapper algorithm for high resolution satellite imagery.International journal of Remote Sensing, 28,3729-3737.

Zhang, Y.J., 1997. Evaluation And Comparison of Different Segmentation Algorithms. Pattern Recogniton Letters, 18,963-974.

URL-1

http://www.harrisgeospatial.com/docs/SievingClasses.ht ml Accessed 19.10.2016.

Copyright (C) International Journal of Engineering and Geosciences (IJEG). All rights reserved, including the making of copies unless permission is obtained from the copyright proprietors. 